\title{
The Effects of Core Stability Exercise on the Ability of Balance in Stroke Patients
}

\author{
김영동, 황병용', 김중환 ${ }^{1}$, 염준우 ${ }^{2}$ \\ 대전성세병원 물리치료실, '용인대학교 보건복지대학 물리치료학과, ${ }^{2}$ 일산백병원 물리치료실
}

The Effects of Core Stability Exercise on the Ability of Balance in Stroke Patients

\author{
Young-Dong Kim, PT, MS, Byong-Yong Hwang, PT, Ph.D ${ }^{1}$, Jung-Hwan Kim, PT, Ph.D ${ }^{1}$, Jun-Woo Yeom, PT, MSc ${ }^{2}$ \\ Dept. of Physical Therapy, Daejeon Sungse Hospital \\ ${ }^{1}$ Dept. of Physical Therapy, College of Health Welfare, Yong In University \\ ${ }^{2}$ Dept. of Physical Therapy, Inje University Ilsan Paik Hospital
}

Purpose Over the last few decades, awide range of exercises have been shown to provide hemiplegic patients a more stable and dynamic balance. Moreover, core stability exercises for hemiplegic patients after a stroke have become increasingly significant in rehabilitation units. Method This study examined the therapeutic effects of the core stability exercises on the static and dynamic balance of hemiplegic patients. A total of 10 hemiplegic patients ( 4 males, 6 females, age ranging from 37 to 81 years) were enrolled in this study. The subjects in the experimental group participated in the core stability exercise program consisting ofa total of 12 sessions 3 times per week, over a 4-week period with each exercise lasting forapproximately 15 minutes. Result The static and dynamic balance by the Berg Balance Scale (BBS) and Timed Up and Go (TUG), respectively, were measured before and after the core stability exercises. A Wilcoxon signed ranks test and Mann-Whitney $U$ test were used to compare the static and dynamic balance before and after the core stability exercises in the hemiplegic patients in each group and inter-groups, respectively. Conclusion The core stability exercises were relatively effective in improving the static balance; BBS. The core stability exercises were quite effective in improving the dynamic balance; TUG $(\mathrm{p}<.05)$. Overall, core stability exercises are believed to be an important therapeutic method in rehabilitation programs for hemiplegic patients.

Key words Core Stability Exercise, Stroke Patients.

교신 저자 황병용, bobathkorea@hanmail.net

논문접수일 2011년 9월 2일

수정접수일 2011년 9월 30일

게재승인일 2011년 10월 20일

\section{I . Introduction}

Hemiplegic patients after a stroke generally suffer impairments of sensation, motion, cognition and emotion, which restricts their basic activities of daily living (Hochstenbach et al, 1996). Neurologic deficits, such as loss of muscle power and impaired balance, are associated with the walking ability (Patterson et al., 2007). Even if hemiplegic patients show some recovery in mobility, compared to healthy adults, they can show difficulties in gait,such as slow gait speed, inappropriate energy expenditure, changed gait kinematics, lack of gait endurance, and poor stability, (Von Schroeder HP et al., 1995). Balance problems commonly occur after stroke, which have been pointed out as a critical health problem in stroke patients (Forster and Young, 1995). These problems affect the activities of daily living (ADL) significantly (Loewen SC, Anderson BA, 1990). Many studies focused not on the balance disability, which is approximately the static or dynamic sitting or standing 
balance, but on the weight distribution, and postural sway (Tyson et al., 2006). Understanding the potential mechanisms that underlie the 'natural' balance recovery is essential for making the proper interventions to improve the balance recovery after stroke (Geurts et al., 2005). Gait training is one of the most important parts in a rehabilitation setting (Mauritz, 2004), and gait reeducation is regarded as a significant physical therapy intervention for hemiplegic patients (Lennon, 2001). Stroke survivors perform home- and community- based gait exercises. Physical activity, such as ambulation activity, is important for functional improvement after stroke (Michael et al,. 2005). The core stability is a terminology describing the lumbopelvic and abdominal region, and is divided into the global and local stability. Like the rectus abdominus, paraspinals and external obliques, superficial, larger muscles around the lumbar and abdominal region contain the global stability muscles, which are the prime mover for trunk or hip flexion, extension and rotation. On the other hand, the transverse abdominis and multifidus muscles located in the intrinsic, deep muscles of the abdominal wall are called the local stability muscles, which provide segmental stability of the spine around the lumbar region (Marshall, 2005). Transversus abdominis $(\operatorname{Tr} \mathrm{A})$, which is one of the abdominal muscles, makes a special contribution to the spinal stability (Hodges, 1999). Moreover, it has been shown that $\operatorname{Tr} A$ is activated before limb movement in healthy people to stabilize the lumbar spine (Akuthota \& Nadler, 2004). Many studies reported a relationship between the core stability exercises for athletes, which confirms the effects of the core stability. With those as a basis, physical therapists have considered core stability exercises in most treatment sessions. However, the approach physical therapists take in the clinical sessions differs according to the patient's case and status. Such considerations might include patients withinjuries from musculoskeletal or cerebrovascular lesions. Accordingly, a further understanding of the effects of core stability exercises affecting the balance is essential for the effective treatment of hemiplegic patients. This study examined the effects of the core stability exercises, which improves the ability of balance.

\section{Method}

\section{Participants and Period}

This study included 10 patients, the experimental and control group of 5 patients each, with hemiplegia aged 37 to 81 who were hospitalized in the Daejoen rehabilitation hospital and diagnosed with stroke resulting in hemiplegia at least in the previous 3 months, and completed the following from April 5th 2010 to April 30th 2010.

The inclusion criteria were as follows:

(1) Gait independently

(2) No orthopedic problems on the lower limb

(3) No major cognitive or perceptual problems

(4) No cardiovascular problems

(5) No visual problems

(6) The ability to understand instructions

\section{Flow Diagram}

Core stability exercises have been carried out 3 times per week over a 4-week period and measured mean of Berg

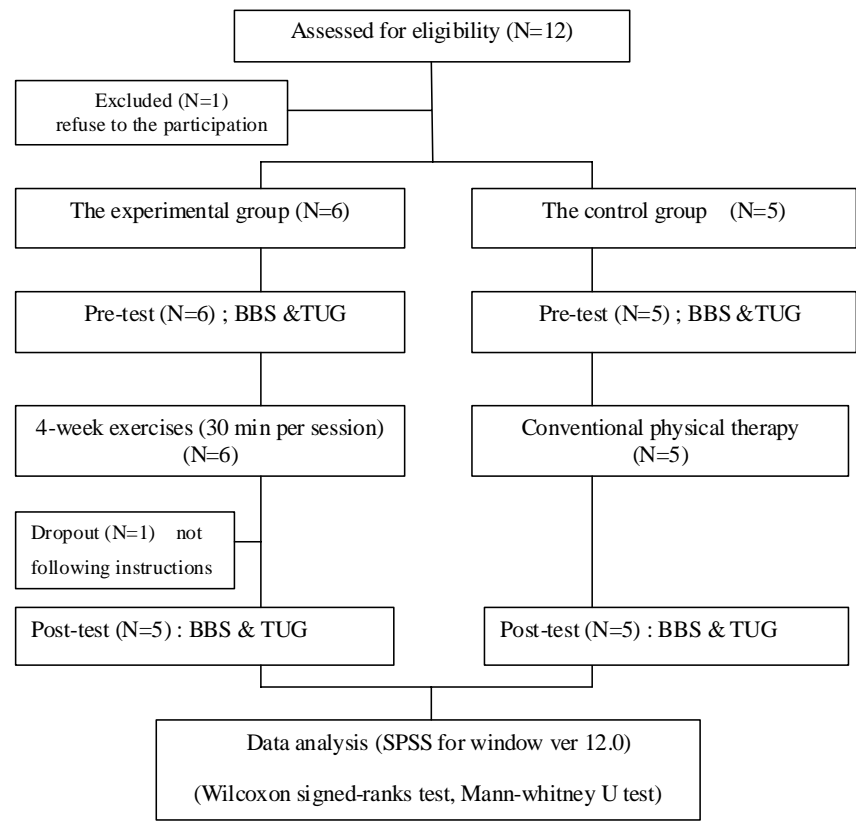

Figure 1. Flow diagram

Balance Scale (BBS) and Timed Up and Go (TUG) before and after core stability exercises. Subjects were initially recruited 12 for this study, but 2 dropped out, one voluntarily and the other for not following the instructions from the tester. 
Flow diagram of the study is given in figure 1 .

\section{Core stability exercises}

Core stability exercises were as follows : The core stability exercises consisted of a total of 12 sessions 3 times each week over a 4-week period with each exercise lasting for approximately 15 minutes.

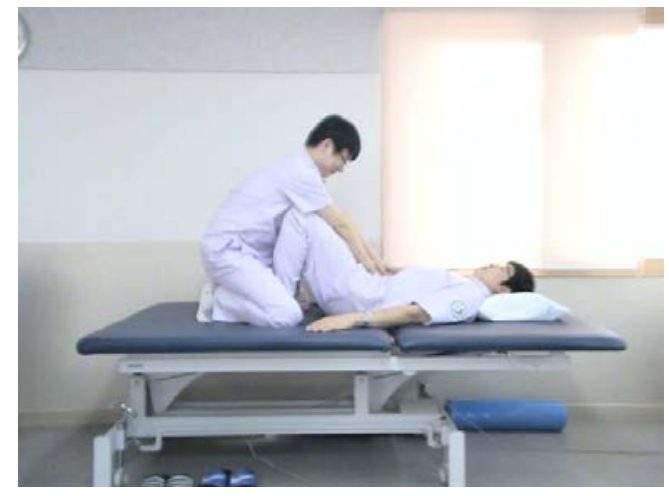

Figure 2. Abdominal breathing

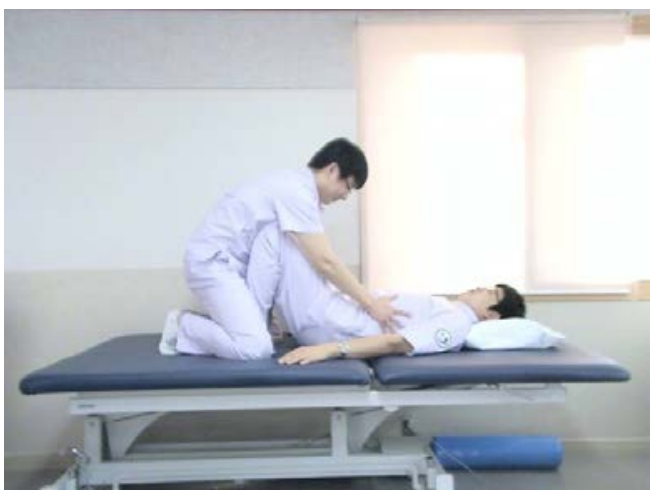

Figure 3. Intercostal breathing

\section{1) Modified breathing exercise}

This exercise makes the transverse abdominis activate in that the mechanical effect of $\operatorname{TrA}$ contraction can control the abdominal content (Goldman et al, 1987). Figure 2 and 3 shows the procedure for the core stability exercise using modified breathing exercise.

(1) A patient lies down on his/her back

(2) Relax the patient's muscle tone on the back of the neck.

(3) Maintain both knee joints at 45 degrees of flexion and spread both knees out to the width of the pelvis.

(4) Put the therapist's hands on the patient's abdominal area and then press slightly (Abdominal breathing).

(5) Should be careful not to move the patient's rib cage upward during inhaling.
(6) Make the patient lift the abdominal area during inhaling for 5 seconds

(7) Make the patient hold on breath for 5 seconds

(8) Make the umbilicus move down and rostrally during exhaling for 5 seconds

(9) Have the patient practice this three of four times and then rest.

(10) Make the therapist's hands move onto both lower ribs (Intercostal breathing).

(11) Make the patient's ribs expand during inhaling and narrow during exhaling.

(12) Have the patient practice this three of four times and then rest.

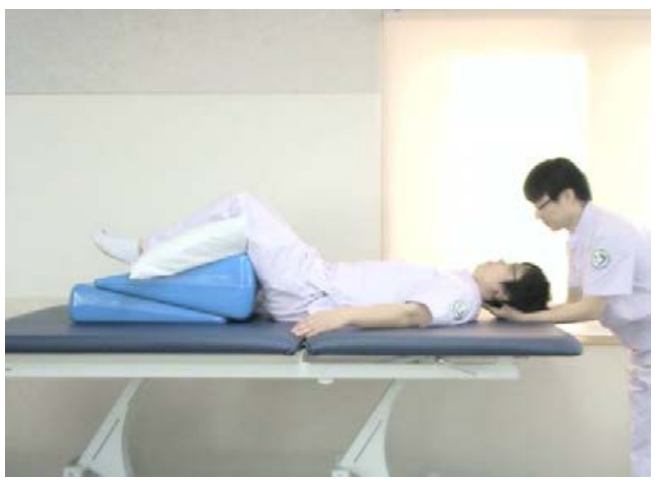

Figure 4. Muscle release

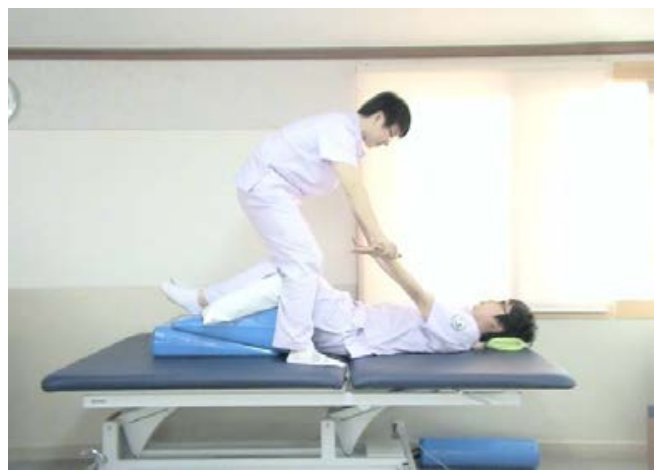

Figure 5. Protraction of both upper limbs

2) Core stability exercise by using a wedge

This exercise activates $\operatorname{TrA}$, internal and external oblique abdominis to stabilize the lower abdominal muscle (Urquhart and Hodges, 1998). Figures 4, 5 and 6 outline the procedure of the core stability exercise using a wedge.

(1) A patient lies down on his/her back

(2) Put a wedge below patient's knee joints to prevent com- 


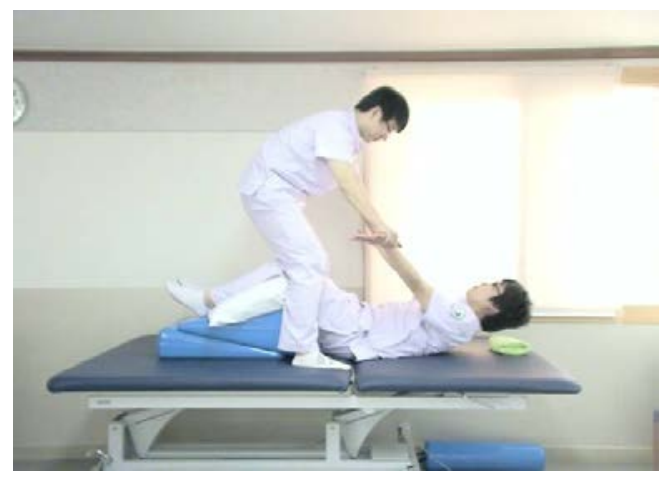

Figure 6. Contraction of transverse abdominis

pensation of the lower limbs lifting during exercising on the supine position

(3) Make patient's pelvis tilt posterior to maintain the muscle tone of the lower abdominis

(4) Maintain the length of the muscle on the back of the neck but neck not to flex it in initiation as well as middle of the exercise.

(5) Release the muscle tone of the rhomboid muscles on the medial boarder of both scapulars to reduce the retraction of the upper limbs.

(6) Stabilize the upper chest to induce the muscle tone of the lower abdominal muscle.

(7) Guide both upper limbs to be protracted by holding the patient's hands.

(8) Make the patient move upper limb anterior and posterior several times to facilitate more the lower abdominal muscles

(9) Make sure not to pull the patient's upper limbs strongly probably causing subluxation of the shoulder joints

(10) Guide the patient to sit up by the therapist.

\section{Measurements}

1) The ability of static balance Berg Balance Scale (BBS) The BBS was created for the elderly individuals to measure balance during a performance. The BBS consists of 14 tasks on a scalefrom 0 to 4 for each task, with 0 indicating an inability to complete the task entirely. Scores can range from 0 to 56 (Steffen TM et al, 2002).

2) The ability of dynamic balance Timed Up \& Go Test (TUG) The way to measure the TUG is that the patients stand up from an armchair then walk a distance of 3 meter, turn, get back to the armchair, and sit down. Meanwhile the tester measures the time from the start to the end. The TUG is a test for basic mobility skill for the elderly (Steffen TM et al,, 2002).

\section{3) Data Analysis}

All the data was analyzed using SPSS (Statistical Package for the Social Science) Version 12.0 for Windows. For the general characteristic of the subjects a mean and a standard deviation were used. A Wilcoxon signed ranks test and Mann-Whitney $U$ test were used to compare the effects of the ability of static and dynamic balance before and after the core stability exercise in patients with hemiplegia in each group and inter-groups respectively. The $a=.05$ level of significance was used for the statistical tests.

\section{Result}

\section{General Characteristics of Subjects}

12 subjects were initially enrolled in this study. However, 2 subjects dropped out, one voluntarily and the other for not following theinstructions from the tester, respectively so that the experimental and control group contained 5 patients each. The remaining 10 subjects aged 37 to 81 included 4 males

Table. 1. General characteristics of the subjects at the baseline

$(\mathrm{N}=10)$

\begin{tabular}{c|ccccc} 
Subject & Sex & $\begin{array}{c}\text { Age } \\
\text { (year) }\end{array}$ & $\begin{array}{c}\text { Paretic } \\
\text { Side }\end{array}$ & Lesion of Site & $\begin{array}{c}\text { Time } \\
\text { Since }\end{array}$
\end{tabular}

Experimental $\operatorname{group}(\mathrm{N}=5)$

$\begin{array}{cccccc}1 & \text { F } & 61 & \text { Right } & \text { CI(Lt MCA) } & 20 \\ 2 & \text { F } & 61 & \text { Left } & \text { S-ICH } & 38 \\ 3 & \text { F } & 66 & \text { Right } & \text { CI(Lt pons) } & 23 \\ 4 & \text { M } & 81 & & \text { S-ICH } & 39 \\ 5 & \text { M } & 51 & \text { Right } & \text { CI(Lt MCA) } & 16\end{array}$

Control $\operatorname{group}(\mathrm{N}=5)$

\begin{tabular}{cccccc}
6 & F & 73 & Left & CI(Rt BG) & 20 \\
7 & F & 77 & Right & Lt periventricular & 51 \\
8 & F & 57 & Right & CI & 12 \\
9 & M & 56 & Right & CI (Cbll) & 39 \\
10 & M & 37 & Left & CI (Rt. pons) & 9 \\
\hline
\end{tabular}

Cl: Cerebral Infarction, BG: Basal Ganglia, Cbll: Cerebellum, MCA: Middle Cerebral Artery, S-ICH: Spontaneous Intracerebral Hemorrhage 
(40\%) and 6 females (60\%). Seven (70\%) and $3(30 \%)$ had a cerebral infarction and cerebral hemorrhage, respectively. The time since the stroke was $2(20 \%)$ below 12 months and 4 (40\%) between 13 months to 24 months, and 4 (40\%) more than 25 months (Table 1).

\section{The Effects of Core Stability Exercises}

1) Variations of the ability of the static and dynamic balance

The experimental group showed improvement in the BBS scores from $41.60 \pm 7.66$ before the core stability exercises to $44.00 \pm 5.52$ after the core stability exercises. On the other hand, the scores in the control group were improved from $47.40 \pm 6.54$ before the core stability exercises to $48.20 \pm 8.70$ after.

The TUG score in the experimental group was reduced significantly from $27.78 \pm 14.37$ before the core stability exercises to $26.34 \pm 13.75$ after $(p<.05)$. In contrast, the score in the control group was reduced from $19.48 \pm 11.83$
Table 3. Individual variations of the BBS and TUG before and after the core stability exercises

$(\mathrm{N}=10)$

\begin{tabular}{|c|c|c|c|c|}
\hline \multirow[b]{2}{*}{ Subject } & \multicolumn{2}{|c|}{ BBS } & \multicolumn{2}{|c|}{ TUG } \\
\hline & $\begin{array}{c}\text { Before } \\
\text { exercise }\end{array}$ & $\begin{array}{c}\text { After } \\
\text { exercise }\end{array}$ & $\begin{array}{l}\text { Before } \\
\text { exercise }\end{array}$ & $\begin{array}{c}\text { After } \\
\text { exercise }\end{array}$ \\
\hline \multicolumn{5}{|c|}{$\begin{array}{l}\text { Experimental } \\
\text { group }\end{array}$} \\
\hline 1 & 32 & 38 & 37.40 & 35.73 \\
\hline 2 & 46 & 47 & 14.18 & 13.89 \\
\hline 3 & 40 & 42 & 21.72 & 20.25 \\
\hline 4 & 38 & 42 & 48.00 & 45.66 \\
\hline 5 & 52 & 52 & 17.60 & 16.17 \\
\hline \multicolumn{5}{|l|}{$\begin{array}{l}\text { Control } \\
\text { group }\end{array}$} \\
\hline 6 & 51 & 53 & 16.11 & 16.27 \\
\hline 7 & 36 & 33 & 40.44 & 39.71 \\
\hline 8 & 52 & 52 & 13.90 & 13.31 \\
\hline 9 & 48 & 54 & 15.23 & 14.24 \\
\hline 10 & 50 & 49 & 11.73 & 10.97 \\
\hline
\end{tabular}

Table 2. Changes in the BBS and TUG and comparison of the groups before and after the core stability exercises ( $\mathrm{N}=10)$

\begin{tabular}{|c|c|c|c|c|c|c|c|}
\hline \multirow{2}{*}{ group } & \multicolumn{2}{|c|}{ Experimental group ( $\mathrm{n}=5$ ) } & \multirow{2}{*}{ z } & \multicolumn{2}{|c|}{ Control group ( $n=5$ ) } & \multirow{2}{*}{ z } & \multirow{2}{*}{$\mathrm{P} * *$} \\
\hline & Pre-test & post-test & & Pre-test & post-test & & \\
\hline BBS & $41.60 \pm 7.66$ & $44.00 \pm 5.52$ & -1.84 & $47.40 \pm 6.54$ & $48.20 \pm 8.70$ & -.36 & 0.34 \\
\hline TUG & $27.78 \pm 14.37$ & $26.34 \pm 13.75$ & $-2.02^{*}$ & $19.48 \pm 11.83$ & $18.90 \pm 11.78$ & -1.75 & 0.07 \\
\hline
\end{tabular}

mean $+\mathrm{SD}$

$*: p<.05$

$p^{* *}$ is a comparison between the experimental group and the control group

before the core stability exercises to $18.90 \pm 11.78$ after (Table 2).

And, there is no significant difference before and after interventions in BBS and TUG between the two groups.

Table 3 lists the individual variations of the BBS and TUG before and after the core stability exercises.

\section{Discussion}

Stroke survivors suffer sensory, musculoskeletal, cognitive and perceptual insults, which impede the balance (Duncan, 1994). The balance is attenuated in hemiplegic patients (Liston and Brouwer, 1996). Hemiplegic patients show twice the postural sway as age-matched people. The normal range of the limits of stability describe the theoretical cone of $8^{\circ}$ anteriorly, $4^{\circ}$ posteriorly and $8^{\circ}$ laterally to either side (Nichols, 1997). Due to the mechanical benefit of $\operatorname{TrA}$ contraction,it is possible to control the abdominal contents, which play a role in respiration by increasing the air flow rate during expiration (Hodges, 1999). TrA arises from the iliac crest, lower six ribs and lateral raphe of the thoracolumbar fascia,and passes medially to the linea alba (Williams et al, 1989). Contractions of the horizontal fiber in the $\operatorname{TrA}$ reduce the abdominal diameter with increased tension in the thoracolumbar fasica and increase the pressure in the intraabdomen. TrA is the first muscle activated. This is because the onset of $\operatorname{TrA}$ is evoked by the CNS, which is pre-programmed prior to moving the limb. In addition, the 
$\operatorname{TrA}$ activates the perturbation caused by the reactive forces on the spine to control the stability of the spine in the feedforward of a predictable disturbance (Hodges, 1999).

This study examined the effects of the core stability exercise on improving the ability of balance. Twelve subjects were initially recruited but 2 dropped out, one voluntarily and the other for not following the instructions from the tester so that the experimental and control group contained 5 patients each.

A previous study reported that a biofeedback and conventional physical therapy program improved the BBS from 45.69 before performing theexercise program to 51.54 after (Geiger et al , 2001). In this study, the mean BBS score in the experimental group increased from 41.60 before the core stability exercises to 44.00 after. In contrast, the mean BBS score in the control group increased from 47.40 before the core stability exercises to 48.20 after. These results show that the core stability exercises were relatively effective in improving the static balance of hemiplegia patients. The ranges of TUG scores have been reported for various samples of elderly people. In previous studies, the mean time of the TUG was 15 seconds in people from health fairs and senior centers (Newton, 1997). In this study, the mean TUG score in the experimental group decreased from 27.78 seconds before the core stability exercises to 26.34 seconds after $(p<0.5)$. On the other hand, the mean TUG score in the control group decreased from 19.48 seconds before the core stability exercises to 18.90 seconds. This suggests that the core stability exercises are effective in improving the dynamic balance in hemiplegic patients. However, there is no significant difference before and after interventions in BBS and TUG between the two groups. Therefore, in both tests, there is somehow better improvement than that in the control group. In particular, the results show that core stability exercises are more helpful in improving the dynamic balance. One reason why there was no significant difference between the experimental and control group in this study might have been the time since the stroke, which means that most subjects in this study were in the chronic stage, and aperiod of 4 weeks for the core stability exercises was not enough time to expect large difference between them.

This study focused on the effects of the core stability exercise on the ability of balance in hemiplegic patients. In addition, the subjects were just enrolled from a definite hospital in Daejon. In addition, the subjects in both groups were a small sample size of 5 subjects in each group. Moreover, core stability exercises were performed 3 days a week, and this study did not consider the effects of other treatment methods used on the other days. Hence, the results may not be due solely to the core stability exercises. Therefore, caution should be taken when generalizing the results of this study to all hemiplegic patients.

The first hypothesis in this study was that the core stability exercises, such as modified breathing exercise and exercises using a wedge that stimulate transverse abdominis, are effective in improving the static balance in hemiplegic patients. Second hypothesis was that the core stability exercises, such as modified breathing exercise and exercises using a wedge that stimulate the transverse abdominus, are effective in improving the dynamic balance in hemiplegic patients. These results highlight the need for a further consideration of core stability exercises in a physical therapy setting to improve the static and dynamic balance of hemiplegic patients.

\section{Conclusion}

This study was performed over one month period from the 5th of April 2010 to the 30th of April 2010 to determine the effects of the core stability exercise on improving the ability of balance. The subjectswere patients with hemiplegia from a stroke and the time since stroke was more than 3 months. The changes in the ability of balance were measured after carrying out core stability exercises over a 4-week period. Core stability exercises were relatively effective in improving the ability of static balance BBS. Core stability exercises were effective in improving the ability of dynamic balance; TUG $(\mathrm{p}<.05)$. These results showed that the core stability exercises are effective in improving the ability of balance in patients with hemiplegia from stroke.

\section{Reference}


1. Akuthota Venu, Nadler SF. Core Strengthening. Arch Phys Med Rehabil. 2004;85(3 suppl 1):S86-92.

2. Clemente CD. In: Gray's Anatomy, 30th ed. Williams \& Wilkins, Baltimore, 1984;490-491.

3. Duncan PW. Stroke disability. Phys Ther. 1994;74(5):399407.

4. Forster A, Young J. Incidence and consequences of falls due to stroke: a systematic inquiry. BMJ. 1995;311(6997): 83-86.

5. Geiger RA, Allen JB, O’Keefe J, et al. Balance and mobility following stroke: Effects of physical therapy interventions with and without biofeedback/forceplate training. Phys Ther. 200181(4):995-1005.

6. Geurts AC, de Maart M, van Nes IJ, et al. A review of standing balance recovery from stroke. Gait and posture. 2005;22(3):267-281.

7. Goldman JM, Lehr RP, Millar AB, et al. An electromyographic study of the abdominal muscles during postural and respiratory manoeuvres. J Neurol Neurosurg Psychiatry. 1987;50(7):866-869.

8. Hochstenbach J, Donders R, Mulder T, et al. Long-term outcome after stroke: a disability orientated approach. Int J Rehabil Res. 1996;19(3):189-200.

9. Hodges PW. Is there a role for transversus abdominis in lumbo-pelvic stability?. Man Ther. 1999;4(2):74-86.

10. Lennon S. Gait re-education based on the bobath concept in two patients with hemiplegia following stroke. Phys Ther. 2001;81(3):924-935.

11. Liston RA, Brouwer BJ. Reliability and validity of measures obtained from stroke patients using the balance master. Arch Phys Med Rehabil. 1996;77(5):425-430.

12. Loewen SC, Anderson BA. Predictors of stroke outcome using objective measurement scales. Stroke. 1990;21(1): 78-81.

13. Marshall PW, Murphy BA. Core stability exercises on and off a swiss ball. Arch Phys Med Rehabil. 2005; 86(2):242-249.

14. Mauritz KH. Gait training in hemiparetic stroke patients. Eur Med Phys. 2004;40(3):165-178.

15. Michael KM, Allen JK, Macko RF. Reduced ambulatory activity after stroke: The role of balance, gait, and cardiovascular fitness. Arch Phys Med Rehabil. 2005; 86(8):1662-1556.

16. Newton RA. Balance screening of an inner city older adult population. Arch Phys Med Rehabil. 1997;78(6):587-591.

17. Nichols DS. Balance retraining after stroke using force platform biofeedback. Phys Ther. 1997;77(5):553-558.

18. Patterson SL, Forrester LW, Rodgers MM, et al. Determinants of walking function after stroke: Differences by deficit severity. Arch Phys Med Rehabil. 2007;88(1): 115-119.

19. Steffen TM, Hacker TA, Mollinger L. Age- and gender test performance in community-dwelling elderly people: Six-minute walk test, berg balance scale, timed up \& go test, and gait speeds. Phys Ther. 2002;82(2):128-137.

20. Tyson SF, Hanley M, Chillala J, et al. Balance disability after stroke. Phys Ther. 2006;86(1):30-38.

21. Urquhart DM, Hodges PW. Differential activity of regions of transversus abdominis during trunk rotation. Eur Spine J. 2005;14(4):393-400.

22. Von Schroeder HP, Coutts RD, Lyden PD, et al. Gait parameters following stroke: A practical assessment. J Rehabil Res Dev. 1995;32(1):25-31. 
